\title{
Authority lies with the institution's IO
}

T he conflict in this scenario arises from a misunderstanding of who at the research facility has authority to revoke approval of an animal research protocol. Citing PHS Policy and the Animal Welfare Act regulations (AWARs), John Callahan, the dean of the Graduate School of Biomedical Sciences at Great Eastern University, mistakenly believes that as an "official" of the institution, he has legal authority to revoke IACUC approval. However, as a member of the IACUC alludes, the definition of an "official" is key. In both the AWARs and PHS policy, the Institutional Official (IO) is defined as a single individual designated by the research institution who is authorized to legally commit on behalf of the institution that the requirements of the animal welfare regulations will be met ${ }^{1,2}$. This person bears ultimate responsibility for the animal care and use program and must have sufficient institutional authority to enforce policies and commit financial resources towards the program. The IACUC reports through the institution's IO.

Revocation, or suspension, of a previously approved protocol can occur in two ways. Typically, suspension occurs via a vote by the IACUC. The AWARs and PHS Policy give the IACUC authority to revoke approval via a majority vote at a fully convened IACUC meeting with a quorum present ${ }^{1,2}$. The IO, in consultation with the IACUC, then reviews the reason for suspension and corrective actions and reports this to applicable regulatory agencies. Alternatively, the IO may independently suspend a protocol if given the institutional authority to do so $^{3}$. Although normally handled by the IACUC, there is nothing in the AWARs or PHS policy that precludes the IO from

\section{A WORD FROM USDA}

In this scenario, a dean of one of the schools of an institution, who is not a member of the IACUC, believes he has the authority as an official of the institution to revoke an IACUC approved protocol that uses pigs for cardiopulmonary resuscitation, because a new human cardiothoracic simulation lab will replace live animal use.

The Animal Welfare Act regulations (AWAR) specify two possible outcomes for an IACUC approved protocol: namely to undergo further appropriate review and approval by officials of the research facility ${ }^{1}$; or suspension by the IACUC during a convened meeting with a quorum present ${ }^{2}$.

An approved protocol may require further review and approval by other officials outside of the IACUC as a result of institutional policies and other regulatory requirements. The regulations only specify that these officials do not have the authority to approve an activity using animals that the IACUC has not approved ${ }^{1}$; as a result, it is left to the institution to determine the appropriate levels of review and approval necessary for the activity to proceed.

Under the AWAR, an Institutional Official (IO) is defined as the individual

at a research facility who is authorized to legally commit on behalf of the research facility that the requirements of the regulations will be met $^{3}$. The institution designates a person to serve as the IO. The dean in this scenario should learn who is serving in that role. The regulations do not give the IO the authority to suspend a protocol. Only the IACUC can suspend a protocol it has approved and the suspension can only occur during a convened meeting with a quorum present ${ }^{2}$. But while an IO cannot "suspend" a research activity in accordance with the regulations, the IO may, depending on the institution's policies, have the authority outside of the Animal Welfare Act regulations to stop an IACUC approved activity.

\section{Betty Goldentyer ${ }^{\bowtie}$}

Deputy Administrator, Animal Care, APHIS,

USDA, Riverdale, MD, USA.

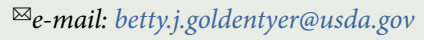

Published online: 24 April 2020

https://doi.org/10.1038/s41684-020-0530-4

References

1. Title 9 Chapter 1 Subchapter $A \S 2.31$ (d)(8)

2. Title 9 Chapter 1 Subchapter $A \$ 2.31(d)(6)$

3. Title 9 Chapter 1 Subchapter $A \S 1.1$ - Institutional Official halting animal research activity ${ }^{3}$. At many institutions, the Attending Veterinarian or the IACUC Chair may also have delegated authority to halt previously approved animal activity. However, this must be followed by rapid IACUC review.

Although not explicitly stated, one can presume that Callahan is not the institution's $\mathrm{IO}$, nor a member of the IACUC, based on the discussion in the committee meeting. $\mathrm{He}$ has somewhat limited knowledge of IACUC processes, has never previously attended a meeting, and it appears clear that the IACUC does not report to him. Therefore, while it could be considered commendable that Callahan is seeking to reduce the number of animals used at the institution, he has no authority to halt the activity himself.

Hopefully, clarification of the AWARs and PHS policy along with further discussion between Callahan and the IACUC Chair and/or committee will resolve the issue. In this scenario, the committee was aware of the new simulation training lab, but based on additional considerations, was comfortable with the use of pigs for training. IACUCs are constituted with representatives from a variety of disciplines, including veterinary medicine, scientific, non-scientific, and the community. This serves to provide both the institution and the public with reasonable assurance that expertise and opinions from various stakeholders are taken into consideration during review, including minority viewpoints.

Theoretically Callahan can elevate his concern to the IO. However, the IO relies on the IACUC's expertise in reviewing protocols to ensure animal welfare and would be unlikely to disagree with the IACUC's decision.

\section{Karen Strait $\bowtie$ \\ The Global Center for Medical Innovation, Atlanta, GA, USA.

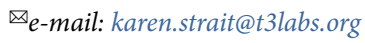

Published online: 24 April 2020 https://doi.org/10.1038/s41684-020-0529-x

\section{References}

1. Public Health Service. PHS Policy on Humane Care and Use of Laboratory Animals. (U.S. Department of Health and Human Services, National Institutes of Health, Bethesda, MD, 2015).

2. United States Department of Agriculture. Animal Welfare Act Regulations. (US Department of Agriculture, Riverdale MD, 2013). 3. Silverman, J., Suckow, M., Murthy, S. eds. The IACUC Handbook. 3rd edition (CRC Press, New York, NY, 2014). 